\title{
ON-SITE MOBILE APPLICATION FOR ENHANCED SAFETY AND QUALITY
}

\author{
Igal M. Shohet ${ }^{1}$, Bhanu Tak ${ }^{2}$, Massimiliano Luzi ${ }^{3}$, and Matty Revivi ${ }^{4}$
}

\begin{abstract}
Two of the most important factors that site managers have to control during construction are safety and quality. We envisage that the emergence of Information and Communications Technology (ICT) systems could be of great use in effectively promoting safety and quality and exploiting the synergy between these two disciplines. The objectives of this research were to investigate the relationship between safety and quality using an on-site mobile application for communication, control and command of construction safety and quality. A system of key safety and quality performance indicators was compiled in order to evaluate the potential benefits. Safety and quality leading indicators were recorded prior and after intervention process using on-site mobile application. The results showed an improvement of 30\% in Quality Indicator (Q.I), $20 \%$ in Safety Indicator 1 (S.I.1) and $42 \%$ in Safety Indicator 2 (S.I.2) and these differences were found to be statistically significant at the level of 0.99 .
\end{abstract}

Keywords: Communication, Control, Mobile technology, Quality, Safety.

\section{INTRODUCTION}

Construction fatalities and injuries continue to be a worldwide plague despite all efforts to enhance safety performance. Safety on construction site appears to be a multifactorial phenomenon gradually related to: culture, project management, contractor organizational parameters, supervision, site conditions, work group and individual characteristics (Choudhry and Fang 2008; Khosravi et al. 2014).

Quality failures, defects and non-conformance are all construction quality issues that may require rework causing major project deviations which have resulted in huge project schedule delays and cost overruns (Love et al. 2015). This is often exacerbated by absence of an integrated safety and quality management system to enhance construction project activities. An integrated safety and quality management system can play a pivotal role in reducing the occurrence of injuries and fatalities and facilitating the completion of project within the allotted budget and on-schedule (Husrul et al. 2008; Li et al. 2015: Zhang et al. 2015).

The objective of the present study was to exploit the emergence of mobile computing technology by development of an on-site mobile application for integrated communication, control and command of construction safety and quality and test such a system. The system was developed within the framework of research towards lean approach to safety

1 Associate Professor, Department of Structural Engineering, Ben-Gurion University of the Negev, Be'er Sheva, Israel, igals@bgu.ac.il

2 M.E. Graduate Student, Department of Civil \& Environmental Engineering, University of Maryland, College Park, Maryland, U.S.A, bhanutak@terpmail.umd.edu

3 M. Sc. Graduate Student, Ben-Gurion University of the Negev, Be'er Sheva, Israel, formerly Università Politecnica delle Marche, Ancona, Italy, massimilianoluzi16@gmail.com

4 Partner and Research, Development and Assimilation Director - Safeguard, Tzur-Hadassa, Israel, mattyr@safeguard.co.il 
and quality management. The underlying rationale is that there is a synergy between high safety and high quality performance and vice-versa and that an on-site mobile application could improve the safety and quality environment of construction sites by focusing on important factors such as leading indicators, work environment indicator, control of key assets and quality key factors. The objectives were as follows:

1. To study the synergy between safety and quality in construction using on-site mobile application for integrated control of safety and quality;

2. To develop the on-site mobile application for integrated continuous improvement of safety and quality performance in construction projects;

3. To examine, measure, and quantify the potential benefits resulting from the implementation of the proposed system in a pilot project through the use of key performance indicators of safety and quality.

\section{RESEARCH METHOD}

The present study was designed to monitor the trend of safety and quality as assessed by leading performance indicators and to examine the relationships between the construction safety and quality resulting from the implementation of such a system in a pilot project. The study has five phases:

1. Establishment and definition of safety performance indicators;

2. Establishment and definition of quality performance indicators;

3. Development and implementation of the on-site mobile application in a pilot project to promote both safety and quality performance;

4. Monitoring the trend of safety and quality performance during the implementation of the application in the pilot study;

5. Evaluation of the results in order to assess the quality and safety benefits accrued following the implementation of the mobile application.

The on-site mobile application relies on a mobile cloud-based system to allow users to manage and communicate safety and quality data in the simplest possible manner by using their smartphones or tablet.

\subsection{Safety Indicators}

The safety performance indicators were defined in terms of workers' behavior, at least 400 data points observations regarding workers' conduct were recorded weekly on-site in each safety sampling. Forty observations at two minute intervals were recorded for a crew of form-workers comprising between ten and twenty workers (different for each sampling due to the dynamic nature of the construction site). In each round, the observers mark individual behavior according to the following categories: "remarkable safe behavior", "safe behavior", "risks himself", "risks others," and "risks himself and others". No data was recorded when a worker could not be observed.

At each safety sampling a performance score was generated and the final score was calculated from: Safety Indicator 1 (S.I.1), which represents the quality of safety behaviors and is calculated as shown in Equation.

$$
\text { S.I. } 1=\sum_{i=1}^{5} P_{i} . W_{i}
$$


Where $\mathrm{P}_{\mathrm{i}}$ is the percentage of the behavior in each of the five categories, and $\mathrm{W}_{\mathrm{i}}$ represents the weight assigned to each category, as follows: (1) remarkable safe behavior, $(0.75)$ safe behavior, (0.5) risks himself, (0.25) risks others and (0) risks himself and others. This weighting system reflects the importance of each category in the total value of the safety performance. The other contribution to the final score comes from Safety Indicator 2 (S.I.2), which represents the percentage of safe activities. This parameter is calculated from the ratio of safe observations (marked under remarkable and safe behavior categories) and the total number of data points collected.

\subsection{Quality Indicator}

Although during initial samplings it was noticed that workers were performing a numerous number of reworks, analysis of the project diaries showed an under reporting of the reworks performed (number and/or the related additional cost and hours), hence negating this parameter as a quality indicator in this case study. Therefore, empirical establishment of suitable quality indicators through direct on site observations was required.

The quality indicator (Q.I.) developed and used in this study is defined by a value between 0 and 100 reflecting the quality state of the reinforced concrete works performed. The parameter was calculated weekly through structured quality samplings and further enables the assessment of the overall quality of the construction works.

In-depth investigation of three quality aspects of the performed reinforced concrete works were carried out: (1) concrete works quality, (2) steel works quality and (3) formworks quality. Key quality parameters were measured for each of the categories according to a five point rating scale and the percentage of correct usage recorded. The final score of the Q.I. was calculated from the average score of the three categories.

\section{DESCRIPTION OF THE ON-SITE MOBILE APPLICATION}

The on-site mobile application provides an innovative solution for continuous improvement of construction safety and quality performance by improving measures for control, monitoring and learning as well as implementing all means necessary to ensure safety and quality (Rozenfeld et al. 2010). Tracing and documentation are carried out by scanning the barcode label attached to assets and helmets of the workers with a mobile phone or tablet that allows the user to collect all the relevant information, including specific activities, time and place accessible to all levels of the project team. The $2 \mathrm{D}$ bar code label allows the supervisor to access the safety and quality key parameters, approving their compliance and the completeness of the performed task by inputting photographs and signatures. As shown in Fig. 1, the application was designed for ease of input without any unnecessary confusion of data, and generates outcome of reports with recommendations to continuous improvement in safety and quality. Supervisors are required by the application to confirm relevant safety and quality key parameters according to (1) formwork safety and quality (according to Israeli Standard 904), (2) quality of concrete works (according to Israeli Standard 118 and 466) and (3) quality of steel works. The on-site mobile application proposed in this study permits a simple and effective unified risk assessment and real-time control by making observation of work (such as lack of PPE, lack of safety equipment, lack of safety check of cranes, etc.) based on location of worker and equipment while minimizing human error and reinforcing an appreciation of safety risks and construction quality. 


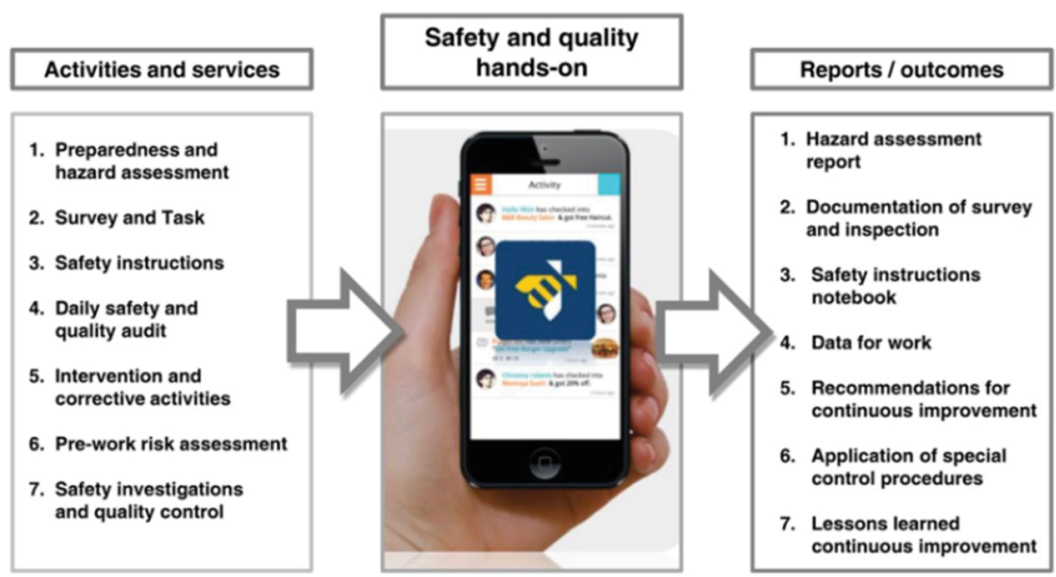

Fig. 1 - Activities, reports and outcomes of the $\mathrm{C}^{4}$ mobile application

\subsection{System architecture}

The mobile application creates a link between the controlled point, labelled with the aid of tag and cloud system that contains all the knowledge, requirements, regulations, information, history and data required for effective real time control of operational processes. The system is composed of the modules shown in Fig. 2. The main features offered by the application are a customizable database that can be adapted to a specific project along with automatic analysis and synchronization of the data which is made available to all levels of the company.

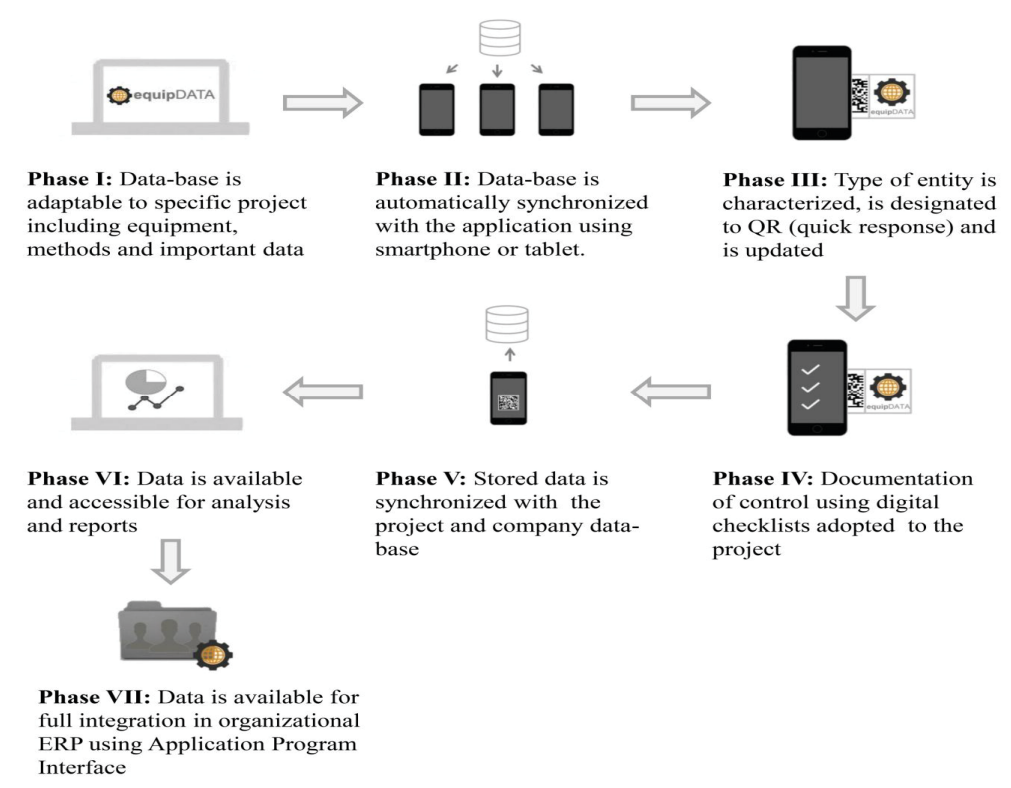

Fig. 2 - On-Site Mobile Application System architecture

\section{SYSTEM IMPLEMENTATION AND MONITORING}

The application is used at three levels of the construction company: Level I - construction engineer and directors at senior company level, such as deputy director for operations and human resources, Level II - safety manager, contractor and subs team leaders and Level III - foreman and crane operators. The application is used for both conducting the safety 
and quality audits and control by the first line management and at the same time provides control-tool for the mid-line and senior level management.

The application produces 200 daily reports and 35 weekly reports covering safety and quality audits, preparedness procedure, and continuous improvement procedures.

\subsection{Pilot Project information}

The proposed system was tested on a 34 floors residential building project in Ramat-Gan (Israel), with an average floor area of 550 sq. m. The total cost is estimated at 25.8 million dollars and the duration of construction is 3 years. The structure workforce comprises of 30 workers with one general contractor and several subcontractors. This construction project represents a professional challenge for the engineers because of the small plot of land where it is realized (900 sq. m.).

\subsection{Monitoring safety and quality performance}

The phases involved in monitoring the trend of the safety and quality performance resulting from the implementation of on-site mobile application were as follows:

1. Base-line phase: This was identified from the initial on-site surveys and represents the starting level of safety and quality performance.

2. Implementation phase: The phase after the base-line phase, during which the application was working and assimilated on the site. Safety and quality observations were carried out during the implementation phase until the indices converged.

\section{FINDINGS AND DISCUSSION}

This chapter describes the findings of safety and quality performance observations consisting of two weeks of base-line phase and nine weeks of implementation phase recorded in time interval of 1 week according to the categories described in detail in section $2.1,2.2$ and 4.2 .

The average score of the Safety Indicators during the base-line phase were $61 \%$ for S.I.1 and $48.8 \%$ for S.I. 2 as shown in Fig. 4 which corresponds to an extremely low index of safety performance. The most frequent hazardous activities detected during this phase were: (1) workers avoided the use of personal protective equipment (2) loads were lifted without a safe harness (3) work was carried out at heights without secure platform (4) workers climbed the formwork and (5) workers threw objects to each other.

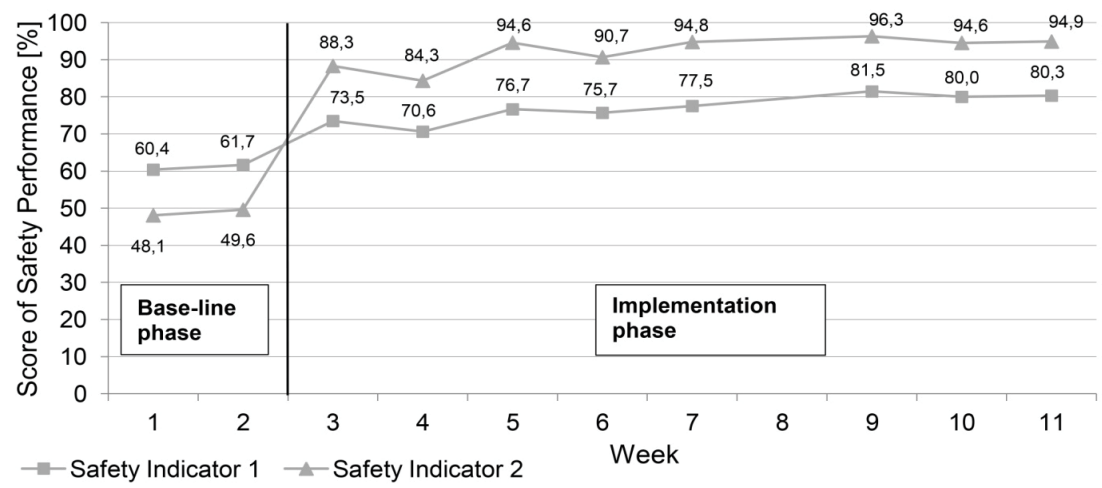

Fig. 4 - Trend of weekly safety performance during the phases of implementation of the on-site mobile application 
Following the implementation of the mobile application, a significant improvement of safety performance over the base-line phase was observed seven weeks after the beginning of the implementation phase. S.I.1 approached the average score of $80.6 \%$ which suggests a qualitative improvement in the workers' safety conduct.

Fig. 5 shows the distribution of the worker's safety behavior observed during the sampling performed in the second week (base-line phase) and Fig. 6 shows the distribution relative to the tenth week (implementation phase) when the application had been well assimilated by the first and mid-line managers. The comparison shows a dramatic decrease in unsafe conduct (categories 1,2 and 3) with the consequent increase of safe behavior (categories 4 and 5) and particularly in the category of remarkable safe behavior (category 5). In fact, S.I.2 approached an average score of $95.3 \%$ representing a reduction from $51.1 \%$ to $4.8 \%$ in unsafe activities/behaviors and thus a $90.8 \%$ less chance of unsafe activity occurrence.

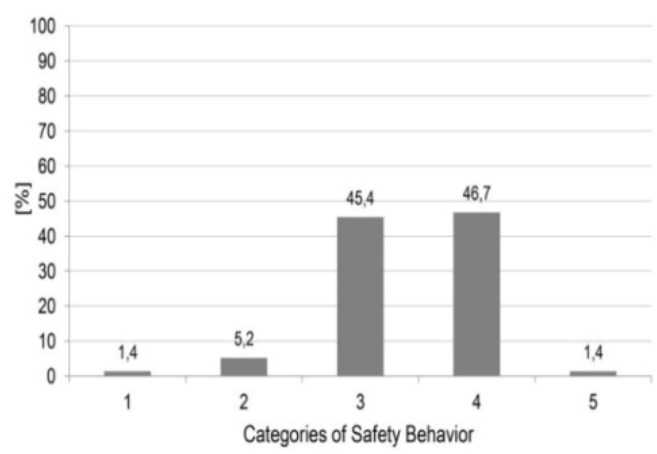

Fig. 5 - Distribution of safety behaviour - Safety sampling week no. 2 [Base-line Phase]

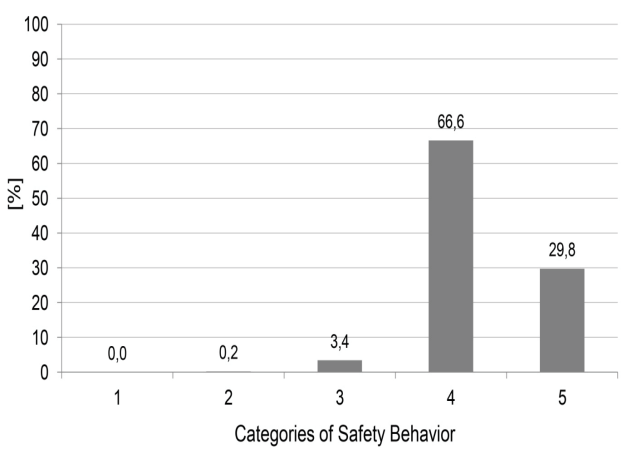

Fig. 6 - Distribution of safety behaviour - Safety sampling week no. 10 [Implementation Phase]

The Quality Indicator score (average of the quality rating for concrete, steel and formworks) was $63.8 \%$ during the base-line phase as shown in Fig. 7 and eventually reached an average of $93.5 \%$ in implementation phase which represents an improvement of $29.7 \%$ as compared to base-line phase. Fig. 8 and Fig. 9 shows the improvement observed in quality of concrete works and steel works respectively during the implementation phase compared to the low initial level (base-line phase).

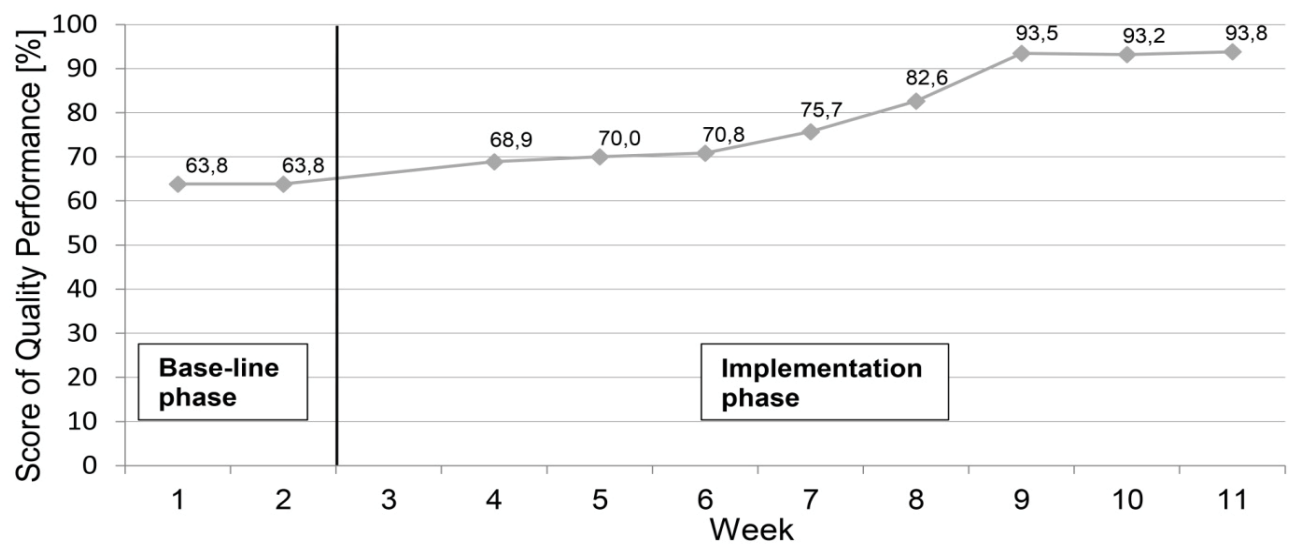

Fig. 7 - Trend of weekly quality performance during phases of implementation of on-site mobile application 
A statistical Student t-test analysis of the safety and quality key performance indicators before and after the implementation of the mobile application demonstrated significant differences at a level of $99 \%$.

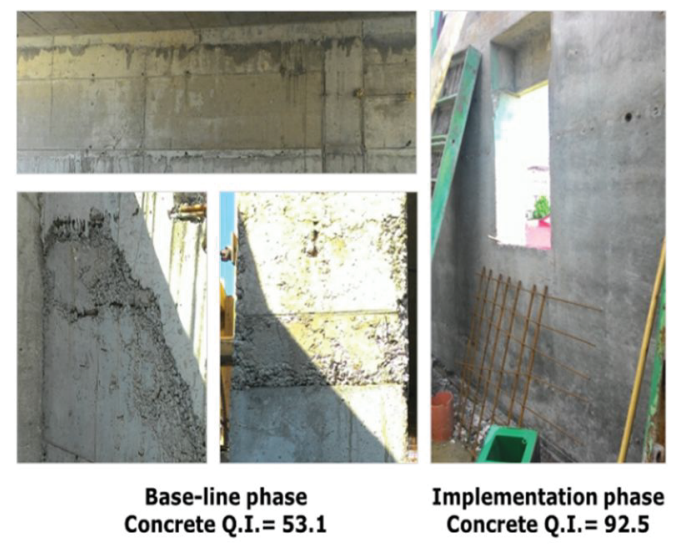

Fig. 8 - Comparison of the quality of concrete works between the two phases of the study

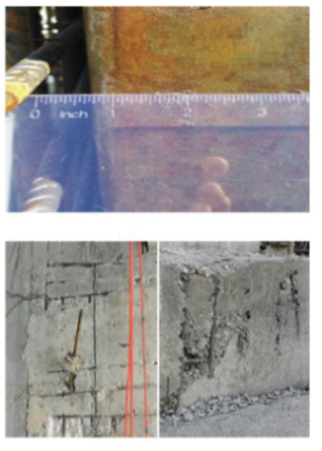

Base-line phase Steel Work Q.I. = 72.0

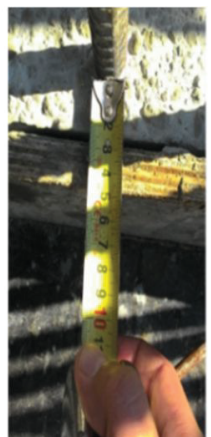

Implementation phase Steel Work Q.I. $=97.0$
Fig. 9 - Comparison of the quality of steel works between the two phases of the study

\section{CONCLUSION}

The objective of this study was to introduce the on-site mobile application and improve communication, control and command of construction safety and quality by the first and mid-line managers. This proposed application is characterized by the following advantages and features:

1. The application facilitates structured risk assessment process and establishes control mile-stones for each activity - thereby contributing to minimization of errors in the safety management process;

2. On the job training technology - The application stimulates the user through an interactive process using lean management philosophy such as training within industry (TWI) (Misiurek and Misiurek 2017) that validates assimilation, understanding and requires judgment of acceptable risks. This process provides users of the application at all levels of management with continuous instruction with respect to the safety regulations and the risk management principles for each specific activity;

3. The technology generates real-time reports of the control variables, facilitating real-time monitoring and remote data analysis at all levels of the organization;

4. The mobile application technology facilitates continuous audits of the safety and quality key performance indicators. This feature accelerates the progress of the safety and quality improvement cycles at the project and the company levels;

5. The application technology facilitates intra and inter-organizational benchmarking of safety and quality using identical protocols.

Safety and quality leading indicators were monitored prior to and after the intervention process. An improvement of 30\% in quality indicator, 20\% in S.I. 1 and $42 \%$ in S.I.2 were accomplished and these differences were found to be statistically significant at level of 0.99 . 
The results clearly indicate the synergy between safety and quality. Quality of construction was improved as a result of reducing the occurrences of defects in the concrete works, steel works and formworks during the construction process. The study provided a clear evidence of effectiveness and benefits of the proposed system by stimulating site management involvement in quality and safety.

However, some caveats of the study should be noted. The large benefit observed may be relevant specifically for construction sectors with safety and quality performance similar to that found in Israel and should be examined in similar sectors in Northern America, Asia and Europe. The proposed system suffers from the following disadvantages: requires time for updating of the records each day; each change of objects in site must be recorded in order to maintain updated safety and quality records and the Geographical Positioning System (GPS) is not yet sufficiently precise at resolution of the site.

\section{ACKNOWLEDGMENTS}

The authors express their gratitude to the Israel Social Security Foundation for work safety

- "Manof" for their generous support of this research.

\section{REFERENCES}

Choudhry, R.M. and Fang, D. (2008). Why operatives engage in unsafe work behavior: Investigating factors on construction sites. Safety Science, 46(4), 566-584.

Husrul, N.H, Kamaruzaman, J. and Hamimah, A. (2008). Management of safety for quality construction. Journal of Sustainable Development, 1(3), 41-47.

Khosravi,Y., Asilian-Mahabadi, H.,Hajizadeh, E. and Hassanzadeh-Rangi, N. (2014). Factors influencing unsafe behavior and accidents on construction sites: a review. International Journal of Occupational Safety and Ergonomics, 20(1), 111-125.

Israeli Standards Institution (1998). Formworks for concrete: Principles. Israeli Standard 904, part 1(in Hebrew).

Israeli Standards Institution (1986). Concrete for structural uses: production control and compressive strength. Israeli Standard 118 (in Hebrew).

Israeli Standards Institution (2003). Concrete code: general principles. Israeli Standard 466 (in Hebrew).

Li, H., Lu, M., Hsu, S. C., Gray, M., \& Huang, T. (2015). Proactive behavior-based safety management for construction safety improvement. Safety Science, 75, 107-117.

Love, P.E.D., Teo, P., Carey. B., Sing C.P. and Ackermann, F. (2015). The symbiotic nature of safety and quality in construction: Incidents and rework non-conformances. Safety Science, 79, 55-62.

Misiurek, K., \& Misiurek, B. (2017). Methodology of improving occupational safety in the construction industry on the basis of the TWI program. Safety Science, 92, 225-231.

Rozenfeld, O., Sacks, R., Rosenfeld, Y., \& Baum, H. (2010). Construction job safety analysis. Safety science, 48(4), 491-498.

Zhang, S., Teizer, J., Pradhananga, N., \& Eastman, C. M. (2015). Workforce location tracking to model, visualize and analyze workspace requirements in building information models for construction safety planning. Automation in Construction, 60, 74-86. 